\title{
MARX E A RELIGIÃO: PRESSUPOSTOS BÁSICOS PARA UMA COMPREENSÃO DA RELIGIÃO NA OBRA DE MARX ${ }^{1}$
}

\author{
Francisco Alencar Mota ${ }^{2}$
}

\begin{abstract}
Resumo: O trabalho se propõe a uma análise da relação entre Marx e a religião, buscando fugir a determinados reducionismos, referindo-se à interpretação que simplifica e generaliza determinada concepção de religião a partir de algumas assertivas de Marx. Para o autor, faz-se necessário compreender tal relação no contexto das obras em que Marx se refere à religião, mais especificamente, o que requer distinguir no pensamento marxiano algumas fases diferenciadas no desenvolvimento de seu pensamento e obras. Nesse sentido, o autor tomou como referências três obras que julgou representativas desse desenvolvimento, em que Marx se refere à religião, comparando-as em função dos dilemas enfrentados por esse autor ao longo de sua vida. A tese do autor é que o foco da crítica da religião em Marx tem como base muito mais, em um primeiro momento, a crítica à filosofia idealista que se apresentava como uma religião; em seguida, uma crítica da alienação humana, compreendida em termos de ideologia religiosa; por último, uma crítica do Capital, que tomara o lugar da divindade, subsumindo o homem como por interior à sua lógica.
\end{abstract}

Palavras-chave: Marx, Religião, Crítica.

Abstract: The paper proposes an analysis of the relationship between Marx and religion, seeking to escape certain reductionism, referring to the interpretation that simplifies and generalizes certain conception of religion from some assertions of Marx. For the author, it is necessary to understand this relationship in the context of the works in which Marx referred to religion, more specifically, which requires distinguishing the Marxian thought some different phases in the development of his thought and works. In this sense, the author took as references three works representative of this development, in which Marx referred to religion, comparing them on the basis of the dilemmas faced by the author throughout his life. The author's thesis is that the focus of Marx's critique of religion is based on much more, at first, the critique of idealist philosophy which presented itself as a religion; then a critique of human alienation, understood in terms of religious ideology; Finally, a review of the capital, which had taken the place of divinity, such as subsuming the man inside his logic.

Keywords: Marx, Religion, Critical.

\footnotetext{
${ }^{1}$ O presente trabalho é a base da comunicação apresentada no III Colóquio Marx, Marxismo e Religião, promovido pelo Grupo de Estudos Marxista - GEM-UFC, no dia 22 de maio de 2014, sediado na Universidade Federal do Ceará - UFC.

${ }^{2}$ Professor Associado da Universidade Estadual Vale do Acaraú - UVA, Mestre e Doutor em Sociologia pela Universidade Federal do Ceará - UFC, Pós-Doutor em Estudos Avançados de Cultura Contemporânea - UFRJ.
} 


\section{Introdução}

Abordar a relação entre o pensamento de Marx e a religião requer um cuidado hercúleo. Isso porque a obra de Marx, entendida aqui como o conjunto de seus escritos, não compreende um todo rigorosamente sistematizado e concatenado, sendo seu pensamento construído historicamente à medida que Marx lidava com diferentes questões práticas e teóricas - controvérsias intelectivas, questões pessoais, engajamento político etc., compreendidas também em termos de "fases". Isso não é verdade somente para com o tema da religião, mas igualmente com sua teoria do Estado, sua teoria das classes sociais, sua teoria da revolução etc. Eis porque falamos em um Marx em oposição ao neo-hegelianismo, um Marx francês, um Marx amigo de Engels, um Marx propriamente revolucionário etc., sem qualquer desmerecimento da assertiva, apenas para facultar a qualquer autor sua condição histórica.

Assim, no que concerne à abordagem da religião, me limitarei à teoria "marxiana", propriamente dita, se é que é possível abordar o pensamento de um autor, livre do que disseram já sobre ele, propondo inicialmente alguns pressupostos iniciais, na forma de questões, que permearão todo o trabalho, a saber: quais escritos, mais especificamente, Marx se refere à religião, sem que eu pretenda abordar todos eles, mas apenas algumas referências escolhidas para o momento? Com que escolas ou autores, Marx está dialogando nesses escritos? E sobre que questões? Qual a relação que Marx estabelece entre a religião e essas questões? A que exemplos de religiões (historicamente falando) Marx se refere propriamente e por que o abordou da forma como o fez?

Tais pressupostos não serão seguidos necessariamente nessa ordem, mas de forma a orientar o trabalho, como um todo, ao final do qual arrisco algumas conclusões, sempre na qualidade de "provisórias", para suscitar uma discussão, muito mais que afirmar posições dogmáticas.

\section{A religião na obra de Marx}

Marx se envolve, de forma mais elucidativa, com o tema da religião em um determinado momento de sua vida, cujo contexto pessoal e histórico pode ser resumido pela sua estada na Universidade de Berlim, no que pese as dificuldades atravessadas, mas igualmente determinante quanto ao curso de sua vida, tendo abdicado da carreira

\begin{tabular}{|l|l|l|l|l|}
\hline Qevista Dialectus & Ano 2 & n. 4 & Janeiro-Junho 2014 & p. 92-105 \\
\hline
\end{tabular}


jurídica, mais especificamente, e assumido a Filosofia e a História com mais intensidade a ponto de, segundo dados de sua biografia, até ter ficado doente. $\mathrm{O}$ clima intelectual estava dominando pelo "hegelianismo", que não se apresentava unicamente como uma corrente filosófica, mas também como ideologia legitimadora do estado prussiano, contra a qual se insurgirá os "jovens hegelianos" (ou "hegelianos de esquerda"), sob uma perspectiva crítica, sobretudo quanto à tese hegeliana de que tal estado era a encarnação dos ideais da moral e a manifestação da razão universal em todas as dimensões da vida social, pensamento dominante na Universidade de Berlim, ao tempo de Marx.

Para se entender a entrada da questão religiosa nas discussões devemos partir, portanto, do pressuposto do pensamento hegeliano de que o Estado, a Religião e a Filosofia, constituíam, para Hegel, supremas manifestações de Deus, entendido como Absoluto, e, no que concerne mais especificamente à religião (a religião cristã, diga-se, sobretudo a luteranismo - religião oficial do estrado prussiano, mas a Igreja Católica, em geral), esta aparecia como a mais completa revelação da Razão enquanto espírito universal.

Posto este pressuposto inicial, necessário à compreensão do desenvolvimento do significado da religião no pensamento de Marx, podemos afirmar que a tematização da religião se dará, inicialmente, no contexto da crítica ao postulado hegeliano que se traduz também em função da oposição ao governo prussiano, o qual redundara numa "frustração", sentida no âmbito do pensamento filosófico pelos denominados "jovens hegelianos", dentre estes Marx, que acabaram por se constituir no que poderíamos dizer grupo "rebelde", vítimas de perseguição.

O tema da religião acabara por se tornar alvo de controvérsias políticas, além, claro, de ponto central da crítica a todo o edifício da filosofia hegeliana, razão pela qual Marx inicia a Introdução à Crítica da Filosofia do Direito de Hegel dizendo: "a crítica da religião é a premissa de toda a crítica"; e no mesmo texto: "a crítica da teologia se converte na crítica da política" (MARX, 2005). A demonstração disso está no próprio trabalho dos jovens hegelianos, os quais escolheram a religião como ponto central de discussão, cada um ao seu modo, buscando minar de forma até certo ponto cuidadosa e estratégica, porém contundente os fundamentos basilares do sistema hegeliano. ${ }^{3}$

\footnotetext{
${ }^{3}$ Refiro-me aos trabalhos sobretudo de David Strauss, Bruno Bauer e Ludwig Feuerbach, abordando, em termos gerais, a religião sob o ponto de vista histórico, como também sua natureza em termos filosóficoantropológico.
}

\begin{tabular}{|l|l|l|l|l|}
\hline Qevista Dialectus & Ano 2 & n. 4 & Janeiro-Junho 2014 & p. 92-105 \\
\hline
\end{tabular}


O foco de crítica ao sistema hegeliano dominante pelos denominados “jovens hegelianos", em um primeiro momento, fora à base filosófica da religião, com implicações diretas na crítica do estado e governo prussiano, que entendiam ser despótico e corrupto. Dentre os "jovens hegelianos" destacara-se Feuerbach, que exercera um papel de liderança sobre os demais, incluindo o próprio Marx. Ao final, não mais encontrando espaço devido a forte censura sofrida pelo governo prussiano, passaram a publicar no exílio, tendo sido os Anais Franco-Alemães, um canal de divulgação de suas idéias, no qual também Marx publicara, de imediato, dois importantes trabalhos importantes para a compreensão do tema da religião - Introdução a uma Crítica da Filosofia do Direito de Hegel e A Questão Judaica, ambos em 1844.

$\mathrm{Na}$ Introdução (2005), Marx dedica o início do texto ao tema da religião, que a apresenta como expressão do desamparo real do homem e protesto contra esse desamparo. Assim o faz em meio a uma análise da situação da Alemanha, marcada pela inércia política, fato esse que se compensa por um modo fantástico da ideologia que é própria religião.

\footnotetext{
A angústia religiosa é ao mesmo tempo a expressão da dor real e o protesto contra ela. A religião é o suspiro da criatura oprimida, o coração de um mundo sem coração, tal como o é o espírito de uma situação sem espírito. É o ópio do povo. (2005)
}

No texto, Marx tem como objeto da crítica o próprio estado e governo alemão, ou o que denominou de o "regime alemão", de caráter anacrônico, em meio à impossibilidade de se enveredar por uma mudança revolucionária do estado de coisas, no máximo, minar os fundamentos idológicos deste estado, realizando a crítica da filosofia alemã, nos termos como elaborados pela filosofia do Direito de Hegel, que servia de base de sustentação ideológica, quanto ao Direito e ao Estado.

$\mathrm{Na}$ Crítica (2005), propriamente dita, Marx se debruça sobre a filosofia do Direito de Hegel, que servira de base legitimadora do Estado moderno, e, mais especificamente, o estado prussiano, para o que Marx propõe que seja realizada a crítica do Estado real que serve de base a esta filosofia. É a crítica dos próprios fundamentos do Estado, que se reveste de religiosidade, sendo a religião, por outro lado, a forma como este Estado se apresenta, ou seja, universal, guardião de toda moral, e desenvolvido. Ao contrário, para Marx, tal estado era despótico e atrasado, e a crítica do mesmo representaria a condição para a saída da opressão e a verdadeira conquista da emancipação humana, rompida a alienação que vivem as massas oprimidas.

\begin{tabular}{|l|l|l|l|l|}
\hline Qenista Dialectus & Ano 2 & n. 4 & Janeiro-Junho 2014 & p. 92-105 \\
\hline
\end{tabular}


É nesse sentido que se enquadra sua abordagem da religião, nos termos como subtraímos ao próprio Marx (2005):

\begin{abstract}
O homem que só encontrou o reflexo de si mesmo na realidade fantástica do céu, onde buscava um super-homem, já não se sentirá inclinado a encontrar somente a aparência de si próprio, o não-homem, já que aquilo que busca e deve necessariamente buscar é a sua verdadeira realidade.

A religião não faz o homem, mas, ao contrário, o homem faz a religião: este é o fundamento da crítica irreligiosa. A religião é a autoconsciência e o autosentimento do homem que ainda não se encontrou ou que já se perdeu. Mas o homem não é um ser abstrato, isolado do mundo. O homem é o mundo dos homens, o Estado, a sociedade. Este Estado, esta sociedade, engendram a religião, criam uma consciência invertida do mundo, porque eles são um mundo invertido. A religião é a teoria geral deste mundo, seu compêndio enciclopédico, sua lógica popular, sua dignidade espiritualista, seu entusiasmo, sua sanção moral, seu complemento solene, sua razão geral de consolo e de justificação. É a realização fantástica da essência humana por que a essência humana carece de realidade concreta. Por conseguinte, a luta contra a religião é, indiretamente, a luta contra aquele mundo que tem na religião seu aroma espiritual.

A miséria religiosa é, de um lado, a expressão da miséria real e, de outro, o protesto contra ela. A religião é o soluço da criatura oprimida, o coração de um mundo sem coração, o espírito de uma situação carente de espírito. É o ópio do povo.

A verdadeira felicidade do povo implica que a religião seja suprimida, enquanto felicidade ilusória do povo. A exigência de abandonar as ilusões sobre sua condição é a exigência de abandonar uma condição que necessita de ilusões. Por conseguinte, a crítica da religião é o germe da critica do vale de lágrimas que a religião envolve numa auréola de santidade.
\end{abstract}

Destaque-se que nessa obra, Marx ainda não tem de forma elaborada ou sistematizada sua teoria das classes sociais, mencionando-a apenas de forma difusa, posto que antecede à fase em que se envolverá mais efetivamente nas lutas em prol dos operários, razão pela qual sua abordagem da religião carece de elementos que serão acrescidos posteriormente, embora que tinha já presente a noção de dialética, daí porque compreenderá a "angústia" religiosa, segundo defendem vários autores, sob uma perspectiva que podemos definir "paradoxal”, compreendendo tanto uma legitimação das condições existentes, como também uma perspectiva de protesto contra elas.

Em Sobre A Questão Judaíca (2010), Marx nos dá mais elementos para a compreensão da religião, importando antes, entender o contexto dessa obra, também escrita no final de 1843, e publicada no ano seguinte, nos Anais. Marx se envolve no problema que se convencionou chamar de "emancipação política", reivindicada pelos judeus alemães, em função do acentuado cristianismo do Estado para o que Bauer respondera sugerindo aos judeus que renunciem ao judaísmo, assim como o homem, em geral, deveria abandonar a religião a fim de obterem a emancipação política e a cidadania.

\begin{tabular}{|l|l|l|l|l|}
\hline Qevista Dialectus & Ano 2 & n. 4 & Janeiro-Junho 2014 & p. 92-105 \\
\hline
\end{tabular}


Marx critica duramente a resposta dada por Bauer alegando que este, limitava o critério da emancipação política unicamente à crítica da religião, transformando um problema que, no fundo, era de outra natureza, em um problema "teológico", o que seria uma contradição, tendo em vista que a emancipação política não poderia ser pensada de forma a desconsiderar o que ele denominara de "emancipação humana". Esta seria obtida apenas de forma integral, tendo-se o homem como uma totalidade, não apenas sua dimensão religiosa, como um problema meamente privado, ressaltando, assim, a contradição entre a esfera privada e a esfera coletiva, a sociedade civil e o Estado, o interesse particular e o geral. Nesse sentido, Marx critica a concepção liberal de direitos humanos, conforme herdada da Revolução Francesa, alegando que tal conquista não superara de vez o "homem egoísta". Tratava-se, portanto, para Marx, de emancipar o homem enquanto ser genérico, emancipação do homem enquanto humano, o que implicaria a sua sociabilidade - os homens entre si, coletivamente. (2010)

É nesse contesto que se compreende o cerne da crítica da religião em Sobre A Questão Judaica, ou seja, sob um duplo aspecto: primeiro, a crítica à concepção do Estado que se constitui como base e estrutura do Estado alemão e, por conseguinte, da Europa do século XIX, em que a religião faz parte do aparato ideológico que o Estado utiliza como forma de alienação; e segundo, pela religião impedir uma conscientização política dos trabalhadores acerca dos problemas reais, rumo a um processo revolucionário de mudança geral do estado de coisas, quando, por exemplo, projeta para uma outra realidade, que não o mundo concreto das relações sociais, a sociedade perfeita desejada.

Marx afirma ser a religião o "ópio do povo" e explicitará em que sentido isso se faz, formulando o conceito de religião como ideologia, ou seja, um sistema de ideias que se caracteriza pela representação de um mundo imaginário oposto ao mundo real de miséria em que vive a classe dos trabalhadores. Conforme suas próprias palavras, a religião "é a realização fantástica da essência humana porque a essência humana carece da realidade concreta".

A religião ocupa, portanto, um papel sobretudo de obstáculo à uma tomada de consciência pelos homens de sua verdadeira situação, fazendo com que estes passem a se preocupar basicamente com um mundo alheio ao seu (o céu, o paraíso, o inferno, etc.) e deixem de perceber a opressão e exploração pelas quais passam aqui neste mundo (terra). Ao contrário, a percebem como vontade divina e não como fruto de um processo histórico-social.

Marx aproveita-se do que considerou ser o "egoísmo dos judeus", alusão à "vocação" monetária e comercial dos judeus, ao exigirem uma emancipação especial

\begin{tabular}{|c|c|c|c|c|}
\hline Qenista Dialectus & Ano 2 & n. 4 & Janeiro-Junho 2014 & p. $92-105$ \\
\hline
\end{tabular}


para si mesmo, reforçando o caráter não religioso do problema religioso, mas engendrado nas estruturas da própria sociedade e do Estado, em particular.

Vós, judeus, sois egoístas quando exigis uma emancipação especial para vós, como judeus. Como alemães, deveis trabalhar pela emancipação política da Alemanha; como homens, pela emancipação humana (MARX, 2000, p. 13).

Para Marx, a questão religiosa que se coloca na obra é a da necessidade de tratar a emancipação humana como um todo indissociável, enquanto emancipação social, não somente de uma classe, para isso importando romper com as amarras e os obstáculos que impedem uma consciência verdadeiramente emancipatória, constituindo-se a religião um desses obstáculos, exatamente por afirmar a verdade de uma ilusão, enquanto que a consciência emancipatória requer a desconstrução dessa ilusão para se enxergar o mundo real, como ele de fato é - um mundo de miséria.

\begin{abstract}
A crítica da religião desengana o homem para que este pense, aja e organize sua realidade como um homem desenganado que recobrou a razão a fim de girar em torno de si mesmo e, portanto, de seu verdadeiro sol. A religião é apenas um sol fictício que se desloca em torno do homem enquanto este não se move em torno de si mesmo (Ibidem, p. 86).
\end{abstract}

Trata-se da crítica do caráter absoluto da religião, compreendida como um existir em si mesmo, posto que quem existe de fato é o homem, constituindo a religião apenas uma forma de representação da realidade que, no contexto da crítica a que se propõe, uma representação às avessas (invertida) da realidade, cumprindo uma função corroboradora da opressão e miséria existente na sociedade (sociedade capitalista), visto que somente no mundo imaginário a religião apregoa a igualdade e a justiça, não no mundo concreto dos homens. Nesse sentido, a religião não é absoluta, não existe independente do homem. Ao contrário é o homem que a cria, e mais do que isso, a cria como forma de resposta falsa aos seus verdadeiros problemas.

A religião não faz o homem, mas, ao contrário, o homem faz a religião: este é
o fundamento da crítica irreligiosa. A religião é a autoconsciência e o auto-
sentimento do homem que ainda não se encontrou ou que já se perdeu. Mas o
homem não é um ser abstrato, isolado do mundo. O homem é o mundo dos
homens, o Estado, a sociedade, este Estado, esta sociedade, engendram a
religião, criam uma consciência invertida do mundo, porque eles são um
mundo invertido (Ibidem, p. 85).

Para Marx, a crítica e a derrota da religião não estão, pois, relacionadas a uma questão teológica, não constitui um fim em si mesmo. Marx não se propõe à crítica da religião pela própria crítica, mas para adentrar o seu fundamento último - o egoísmo humano que impede uma representação mais coletiva da vida social e, particularmente, da opressão humana. Assim, não se trata de acabar com a religião em si, mas acabar

\begin{tabular}{|l|l|l|l|l|}
\hline Qevista Dialectus & Ano 2 & n. 4 & Janeiro-Junho 2014 & p. 92-105 \\
\hline
\end{tabular}


com um modelo de sociedade que cria uma religião que obstaculiza a emancipação humana. Não se trata de um problema teológico, mas político e social.

[...] o dinheiro é o Deus zeloso de Israel, diante do qual não pode legitimamente prevalecer nenhum outro Deus. O dinheiro humilha todos os deuses do homem e os converte em mercadoria, [...], o dinheiro é a essência do trabalho e da existência do homem, alienada deste, e esta essência o domina e é adorada por ele. O Deus dos judeus se secularizou, converteu-se em Deus universal. A letra de câmbio é o Deus real do judeu (MARX, 2000, p. 48).

Em A Ideologia Alemã, obra em que Marx a escreve conjuntamente com Engels, no exílio, tem-se o tema da religião pulverizado em meio a outras formas de representação da realidade, desta feita sob o manto da noção de ideologia, como forma de consciência, ao lado de outras formas como a própria ciência e toda a produção de ideias. A tese principal defendia por Marx (e Engels), conforme ele mesmo nos oferece é:

a produção de ideias, representações, da consciência está de início imediatamente entrelaçada na atividade material e no intercâmbio material dos homens, linguagem e vida efetiva (...) o mesmo vale para a produção intelectual tal como se apresenta na linguagem da política, das leis, da moral da religião, da metafísica etc de um povo. (MARX; ENGELS, 1986, p. 36)

Na obra, Marx se encarregará de fazer a crítica da crítica à filosofia alemã, realizada pelos neo-hegelianos, sobretudo de Feuerbach, Bruno Bauer e Max Stirner, de quem definitivamente agora se separa, atribuindo-lhes o fato de que se limitavam, ainda, às representações religiosas do pensamento de Hegel, não ocorrendo de "perguntarem qual era a conexão entre a filosofia alemã e a realidade alemã, a conexão entre a crítica e o seu próprio meio material”.

Ao adentrar o mérito da questão, Marx introduz diversas noções que comporão o conteúdo da obra, tais como noção de consciência, divisão do trabalho, comunismo, proletariado, classe social, força produtiva, intercâmbio produtivo, propriedade privada, atreladas à outras já desenvolvidas como de Estado, alienação etc, buscando uma relação entre tais noções, de onde chega-se a uma noção mais ampla que lhe redundou inclusive o legado de método científico a saber - o seu materialismo histórico.

Não se trata mais de fazer a crítica dos fundamentos da filosofia de Hegel, mas afirmar que a crítica dos neohegelianos (esquerda hegeliana) não fora suficiente para romper definitivamente com as contradições daqueles fundamentos, em termos de representações religiosas. Faltara a eles, segundo Marx, "perguntar pela interconexão

\begin{tabular}{|l|l|l|l|l|}
\hline Qepista Dialectus & Ano 2 & n. 4 & Janeiro-Junho 2014 & p. 92-105 \\
\hline
\end{tabular}


da filosofia alemã com a realidade efetiva alemã, pela interconexão da crítica deles com a própria circunstância material deles".

Se propondo a isso, Marx elege como fator inovador de sua análise levar à radicalidade "a existência de indivíduos humanos vivos", a assertiva de que "o modo pelo qual os homens produzem os seus meios de vida depende inicialmente da constituição mesma dos meios de vida encontrados aí e a ser produzidos”. Inverte, pois, o sistema do pensamento alemão de cabeça para baixo, priorizando o homem em toda a sua extensão histórica, imerso em suas próprias cadeias produtivas, como elas se configuram no mundo concreto, na vida prática, para, só então, subir à formação da consciência, esta atrelada a essa condição existencial que, na forma de ideologia, propicia ao homem pensar sua existência de forma invertida, contraditória, legitimadora do status quo.

Ao mesmo tempo em que as formas de representação espiritual (entenda-se, moral, jurídica, política, religiosa etc) emergem das condições mais materiais do indivíduo concreto, possuem, em função dos poderes estabelecidos, a capacidade de representar falsamente as condições sociais existentes no interior das relações de produção. É-nos possível dizer, em consonância com o pensamento de Marx, que os homens produzem suas ideias, mas nem sempre produzem como as querem.

Nesse sentido, a religião passa a se configurar como um modo de alienação que, nessa obra, ganhara contornos diferenciados em relação a outras obras, como, por exemplo, nos Manuscritos Econômicos e Filosóficos, de 1844. Na Ideologia Alemã a alienação, incluindo a religiosa, é tida como força produtiva, graças à cooperação dos indivíduos na divisão do trabalho, mostrando-se aos homens como um "poder estranho, situado fora deles, que eles não conseguem mais dominar", e que, na verdade, dirige a vontade e a marcha da humanidade.

Parece-nos que, após A Ideologia Alemã, presenciamos uma relativa mudança de foco no concerne à abordagem da religião por Marx, em termos de como vinha sendo tratando até então. As referências à religião se darão de forma mais difusa, não mais como uma espécie de subsistema ideológico de representação da consciência, ou de fundamento da concepção de Estado ou mesmo do pensamento filosófico alemão; mas como forma de existência e atuação do próprio Capital, sobretudo no que exerce sobre a sociedade e aos indivíduos, como podemos perceber de diversos trechos dispersos em obras como o próprio Capital.

\begin{tabular}{|l|l|l|l|l|}
\hline Qevista Dialectus & Ano 2 & n. 4 & Janeiro-Junho 2014 & p. 92-105 \\
\hline
\end{tabular}


O capitalismo se transforma na religião na modernidade, o Capital o grande deus e a mercadoria o objeto de adoração, daí o "fetichismo da mercadoria"; os fiéis, as grandes massas de trabalhadores, sendo o "sacrifício" ou a "oferenda" ao Deus-Capital a venda da força de trabalho, enquanto sacrifício humano, e as bênçãos os sonhos ilusórios de uma vida melhor, como podemos depreender da crítica de Marx à economia política. No entanto, vale salientar o caráter metafórico dessas referências, sem qualquer pretensão, julgo eu, de conferir a esses conceitos religiosos um conteúdo mesmo que de simbolismo cultural à exemplo do que ocorre nas ciências da religião propriamente ditas. Talvez nesse ponto Marx se diferencie de Engels, que em diversos dos seus textos parecia perseguir algum significado cultural e histórico para a religião (ou as religiões históricas), talvez mesmo em função de sua educação protestante. Sobretudo quanto às associações entre comunismo e religiosidade popular, tópico que poderia ser melhor perseguido por meio da pesquisa.

\section{Considerações finais}

Apresentada uma síntese do desenvolvimento ou "usos" da noção de religião em Marx a partir de alguma de suas obras em que trata mais diretamente do tema, não podemos deixar de responder algumas perguntas que não param nunca de ser feitas: qual a relevância da abordagem de Marx acerca da religião para a compreensão do fenômeno religioso hoje? O que Marx disse sobre a religião se aplica a qualquer forma de religião histórica? Tinha Marx em mente uma análise da religião, propriamente dita? Esta mesma pergunta, de outra forma: existe uma teoria da religião stricto sensu em Marx?

Obviamente que ao tentar responder a essas questões imprimimos às respostas um quantum de subjetividade, mesmo que sob pretensão analítica. E que qualquer resposta que arrisquemos a essas perguntas estará estritamente relacionada com nossas histórias de vida, nossas constituições psicológicas e emocionais.

No entanto, é-nos possível correr esse risco, além do que de nada valeria a mera ânsia de conhecimento se não visássemos uma mediação entre a contribuição teórica que a filosofia (e a ciência, de uma maneira geral) produzisse e a prática humana e social, entendida aqui como o conjunto das circunstâncias e situações concretas que estão a clamar por esclarecimentos, orientação e mudança. Afinal, não é do próprio

\begin{tabular}{|l|l|l|l|l|}
\hline Qenista Dialectus & Ano 2 & n. 4 & Janeiro-Junho 2014 & p. 92-105 \\
\hline
\end{tabular}


Marx o legado de que a ciência e a filosofia só fazem sentido se responderem e orientarem situações concretas da vida social - no caso, a prática revolucionária?

No entanto, para isso é preciso por o trem em cima dos trilhos! O que quero dizer com isso? Por as coisas nos seus devidos e corretos lugares! Não podemos, sob pena de não estarmos sendo "marxista", ignorar o caráter histórico dos fenômenos com os quais lidamos, proceder as devidas distinções e diferenças, compreender o significado das teorias e resultados científicos não como dogmas a serem aceitos de forma incondicional e supra histórica sob o manto falso da coerência identificatória que possuímos com os autores que mais "nos agradam". Guardo como um dos principais ensinamentos de Marx o exposto na seguinte sentença: "ser radical é tomar as coisas pela raiz. Ora, a raiz, para o homem, é o próprio homem". Tal assertiva faz-nos ver que uma crítica só faz sentido se ela responder aos problemas suscitados pelo homem. Assim como também que o homem não cria problemas que no fundo, no fundo, não lhe interessa em sua vida prática.

Em se debruçando sobre os textos de Marx que tratam da religião, podemos, de imediato, auferimos uma conclusão: não se encontra em momento nenhum Marx se referindo à religião, em abstrato, ou seja, fora de um contexto histórico o qual busca compreender, como, por exemplo, a situação política da Alemanha; a luta revolucionária em que se engaja, posteriormente, a forma que assume o Capital perante os homens e a sociedade. Só em atrelando sua abordagem sobre a religião a um determinado contexto, em específico, é que a compreensão da religião adquire sentido. Mesmo quando Marx se refere a experiências religiosas em concreto como o cristianismo, o luteranismo, ele tem em mente o luteranismo alemão, não o que existe no sul do Brasil, na Argentina ou em outras partes do mundo. Tudo o que ele se referiu sobre a religião encontra num determinado contexto histórico uma significação que a genialidade de Marx soubera muito bem transformar numa teoria devidamente elaborada e coerente.

Não se pode afirmar categoricamente que Marx procedera uma análise stricto sensu da religião. No entanto, em se debruçando sobre determinados textos em que Marx trata da religião, não nos será difícil perceber que nosso autor tem em mente muito mais em falar de uma filosofia que se travestia de religião do que de uma religião em si mesma; falar do Capital que se transveste de religiosidade do que uma religião que engendera o Capital. Isso seria coerente com o fato de que o foco de Marx não era determinada religião, em particular, como em Weber, Durkheim etc, que se debruçaram

\begin{tabular}{|l|l|l|l|l|}
\hline Qevista Dialectus & Ano 2 & n. 4 & Janeiro-Junho 2014 & p. 92-105 \\
\hline
\end{tabular}


sobre o significado social dos sistemas simbólicos das religiões em particular que analisaram. O foco da crítica de Marx era a filosofia idealista, em um primeiro momento, que se apresentava como uma religião; mais tarde, a alienação humana, compreendida em termos de "idolatria" religiosa; o Capital, que tomara o lugar da divindade e subsumia o homem, e assim por diante. Marx não se debruça sobre questões religiosas propriamente ditas, nem mesmo como filósofo ou cientista social, a despeito de se referir vez ou outra a determinadas religiões históricas. Marx nunca analisou uma determinada religião, em particular, daí não podermos inferir uma filosofia da religião amparado nas referências que faz à determinada religião. Se levarmos mais adiante essa tese, pode-se afirmar, sem qualquer desmerecimento da abordagem de Marx sobre a religião, que os elementos que ele toma da religião são desprovidos de análise mais profunda, muito mais próximo do senso comum do que de uma "ciência religiosa", propriamente dita; isso porque não era sua intenção proceder, como tentou-se abordar no presente trabalho, uma compreensão do sistema religioso de qualquer religião, apenas compreender o que verdadeiramente era seu objeto de análise e crítica - o sistema de reprodução capitalista, suas característica, conteúdos, articulações, mediações e estratégias. Tanto é que no Prefácio da Contribuição à Crítica da Economia Política (, ele explicita sua abordagem do modo de produção capitalista dizendo que alterara a ordem das coisas explicando as formas de consciência (jurídicas, políticas, religiosas, artísticas ou filosóficas) pelas contradições da vida material, definidas em termos de conflitos existentes entre as forças produtivas sociais e as relações de produção. Aqui, como em outros momentos, Marx explicita o objeto de sua análise, deixa claro o que ele verdadeiramente analisara, e o fizera muito bem. Não se trata de submeter Marx a uma crítica, propriamente dita, ao contrário, conferir justiça ao autor, o que muitas vezes vimos ser injustiçado por compreender a religião dessa ou daquela forma. Trata-se, na verdade, de se fazer justiça a Marx, evitar que seja julgado por um crime que não cometera, muitas vezes denunciado pelos seus próprios discípulos que afirma apressadamente que Marx pensa isso ou aquilo da religião.

Isso não significa que muitas experiências religiosas não estejam cumprindo o papel que Marx revelara - submetendo pessoas inclusive de todas as classes e camadas sociais a uma condição de humilhação, engano, subordinação incondicional, enfim "alienação" nos termos mesmos estabelecidos por Marx, como se pode observar em muitas experiências religiosas.

\begin{tabular}{|l|l|l|l|l|}
\hline Qenista Dialectus & Ano 2 & n. 4 & Janeiro-Junho 2014 & p. 92-105 \\
\hline
\end{tabular}


No entanto, experiências religiosas existem que apregoam a relação com a divindade como forma de libertação e emancipação humana, inclusive em termos políticos, sociais e econômicos, esferas essas trazidas para dentro do sagrado e não excluídas dela, à exemplo do que ocorrera sobretudo ao longo das décadas de 1970 e 1980, e até hoje, na América Latina, dentro do próprio cristianismo católico e protestante, à luz da Teologia da Libertação, em que a experiência religiosa é vivida pelas comunidades de forma a compreender a emancipação religiosa no contexto das lutas políticas, econômicas e sociais em prol da emancipação humana. 


\section{Referências Bibliográficas}

MARX, Karl. Crítica da Filosofia do Direito de Hegel. São Paulo: Boitempo, 2005. . Manuscritos Econômico-Filosóficos. São Paulo: Boitempo, 2004. . Sobre A Questão Judaica. São Paulo: Centauro, 2000.

. Coleção Grandes Cientistas Sociais - Sociologia. Org Otávio Ianni. São Paulo: Ática, 1987.

ENGELS, Friedrich. Coleção Grandes Cientistas Sociais - Política. Org. José Paulo Netto. São Paulo: Ática, 1981.

MARX, Karl; ENGELS, Friedrich. A Ideologia Alemã. 5a . Ed. São Paulo, Hucitec, 1986.

.; Coleção Grandes Cientistas Sociais - História. Org. Florestan Fernandes. São Paulo: Ática, 1984. 